\title{
From Formalism to Feminism: Gender, Business and Human Rights
}

\author{
Nora Götzmann $^{1 *}$ (D), Joanna Bourke Martignoni ${ }^{2}$, Bonita Meyersfeld ${ }^{3}$ (D) and Harpreet Kaur ${ }^{4}$ \\ ${ }^{1}$ Chief Adviser, Human Rights and Business, The Danish Institute for Human Rights, Denmark's \\ National Human Rights Institution; Adjunct Researcher, Centre for Social Responsibility in Mining, \\ Sustainable Minerals Institute, The University of Queensland, Australia \\ ${ }^{2}$ Senior Research Fellow at the Geneva Academy of International Humanitarian Law and Human Rights; \\ Affiliate of the Gender Centre at the Graduate Institute in Geneva, Switzerland \\ ${ }^{3}$ Associate Professor, University of the Witwatersrand Law School; Advocate of the High Court of \\ South Africa \\ ${ }^{4}$ Business and Human Rights Specialist, United Nations Development Programme, Asia-Pacific \\ *Corresponding author. Email: nog@humanrights.dk
}

\begin{abstract}
This special issue uses feminist perspectives to explore the field of business and human rights (BHR). Gendered inequalities, based on embodied, assigned or presumed gender identities and sexual orientations, have long been eclipsed from international law; the same has occurred in BHR. Rarely is gender addressed holistically to fully encompass the systemic discrimination and deep-seated patriarchal and neo-colonial structures that create and perpetuate inequalities. The contributions in this special issue challenge both the absence of attention to gender in BHR as well as conventional approaches used to address gendered inequalities within BHR discourses and frameworks. Three recurring themes characterize the special issue: (1) bodies and embodiment; (2) women's positionality in the marketplace; and (3) borderlessness. Collectively, the contributions proffer feminist approaches to BHR that embed gender justice as foundational, rather than an afterthought.
\end{abstract}

Keywords: intersectionality; LGBTI + rights; non-discrimination and equality; United Nations Guiding Principles on Business and Human Rights (UNGPs); women's rights

\section{Introduction}

Feminist theorists have long criticized the invisibility of gendered inequalities in international law. ${ }^{1}$ The field of business and human rights (BHR) is no exception. From its inception, until recently, foundational BHR frameworks and many of the actors working on their development and implementation have been blind to gender differences, and assumed

\footnotetext{
${ }^{1}$ Bonita Meyersfeld, 'Business, Human Rights and Gender: A Legal Approach to External and Internal Considerations' in Surya Deva and David Bilchitz (eds.), Human Rights Obligations of Business: Beyond the Corporate Responsibility to Respect (Cambridge: Cambridge University Press, 2013) 193; Hilary Charlesworth, Christine Chinkin and Shelley Wright, 'Feminist Approaches to International Law' (1991) 85:4 American Journal of International Law 613.

(c) The Author(s), 2022. Published by Cambridge University Press.
} 
that all people who experience human rights harms experience them in the same way. ${ }^{2}$ This is something of a paradox, given that the BHR field developed specifically to reveal, and respond to, the unequal power structures that create and perpetuate human rights abuses associated with business activities. ${ }^{3}$ The gender-blind approach to BHR has led to gaps in the way that states define and exercise their duty to protect; how businesses undertake human rights due diligence; the manner in which grievance resolution and remedies are designed; and, not least of all, in academic theorizing.

In the last few years, however, this status quo has gradually started to shift. Many working in the BHR field have begun to appreciate the importance of approaches that identify and confront unequal power relations. ${ }^{4}$ This makes space for the construction of BHR principles that more fully observe and respond to the full range of business-related human rights harms and concomitant responsibilities..$^{5}$ Civil society organizations, governments and inter-governmental organizations have started to focus on how unequal social, economic and political structures are replicated or exacerbated by businesses. ${ }^{6}$ However, too frequently gender remains an add-on to corporate responsibility and accountability. Much like women in society, gender in the BHR discourse has been 'othered'.

There is a myriad of ways in which different people experience human rights violations, abuses and harm. Our view is that 'gender' or a 'gendered analysis' is about understanding that there are many, dynamic experiences of gender(s) and sex. This heterogeneity of experience requires more than a separate set of principles on 'women and children' or 'LGBTI+ issues' in BHR discourse. Gender demands that we recognize that the structures of harm to which BHR responds, are not neutral but multifaceted, intersectional, fluid and context-specific. As such, gender is distinctly relational, where the distribution of power and resources among people is critical for understanding how their engendered social and biological roles and responsibilities are constructed and exercised. While we seek to move beyond a binary approach in favour of a more inclusive and dynamic understanding of gender, most of the contributions in the special issue focus on the situation and positionality

\footnotetext{
${ }^{2}$ Joanna Bourke Martignoni and Elizabeth Umlas, 'Gender-Responsive Due Diligence for Business Actors: Human Rights-Based Approaches', The Geneva Academy of International Humanitarian Law and Human Rights (2018), https:// www.geneva-academy.ch/joomlatools-files/docman-files/Academy\%20Briefing\%2012-interactif-V3.pdf (accessed 11 November 2021); Nora Götzmann and Nicholas Brainton, 'Embedding Gender-Responsive Approaches in Impact Assessment and Management' (2021) 39:3 Impact Assessment and Project Appraisal 171; Meyersfeld, note 1; Penelope Simons and Melisa Handl, 'Relations of Ruling: A Feminist Critique of the United Nations Guiding Principles on Business and Human Rights and Violence Against Women in the Context of Resource Extraction' (2019) 31:1 Canadian Journal of Women and the Law 113; Beth Goldblatt and Shirin Rai, 'Remedying Depletion Through Social Reproduction: A Critical Engagement with the United Nations' Business and Human Rights Framework' (2020) 3:2 European Journal of Politics and Gender 1.

${ }^{3}$ Human Rights Council, 'Protect, Respect and Remedy: A Framework for Business and Human Rights', A/HRC/8/5 (7 April 2008).

${ }^{4}$ Human Rights Council, 'Gender Dimensions of the Guiding Principles on Business and Human Rights: Report of the Working Group on the Issue of Human Rights and Transnational Corporations and Other Business Enterprises', A/HRC/41/43 (23 May 2019); Business and Human Rights Resource Centre, 'Gender, Business \& Human Rights', https://www.business-humanrights.org/en/big-issues/gender-business-human-rights/ (accessed 11 November 2021).

${ }^{5}$ See, e.g., OHCHR, Tackling Discrimination Against Lesbian, Gay, Bi, Trans \& Intesex People: Standards of Conduct for Business (New York: OHCHR, 2017).

${ }^{6}$ See, e.g., Human Rights Council, note 4; Linnea Kristiansson and Nora Götzmann, 'National Implementation Processes for the UNGPs: Towards Gender-Responsive Approaches' (2020) 26:1 Australian Journal of Human Rights 93; Marianna Leite and Matti Kohonen, 'Engendering Business and Human Rights: Applying a Gender Lens to the UN Guiding Principles on Business and Human Rights and Binding Treaty Negotiations', Christian Aid (2021), https:// www.christianaid.org.uk/sites/default/files/2019-05/Engendering\%20Business\%20and\%20Human\%20Rights_ 1.pdf (accessed 11 November 2021).

7 On women as 'the other' see, e.g., Simone de Beauvoir, The Second Sex (Harmondsworth, Middlesex: Penguin Books, 1949).
} 
of those who identify or are viewed as women and girls, rather than exploring issues of inequality based on sexual orientation and gender identity. Collectively, however, the contributions demand that we abandon assumptions of homogeneity in BHR, both in our analysis of harm and in our development of the norms designed to address such harm.

The contributions in this special issue demonstrate that a feminist approach to BHR cannot be reduced to simply incorporating 'vulnerable' or 'marginalized' groups into existing, unequal institutions and structures. Instead, it must also involve observing and reimagining purportedly immutable frameworks, and disrupting and reimagining the unequal power relations created and perpetuated through business activities and heteronormative approaches to BHR.

From the diverse contributions, three recurring inter-connected themes emerge: (1) bodies and embodiment; (2) women's positionality in the marketplace; and (3) borderlessness. While this special issue cannot capture the spectrum of subjects that demand a gendered analysis, we hope that it adds to conversations on gender, exclusion and silencing in BHR theory and practice.

\section{Gender in Business and Human Rights and the Need for Feminist Approaches}

To date, the integration of gender in BHR has been heavily influenced by neoliberal thinking and the related 'business case' for gender equality. ${ }^{8}$ Approaches frequently deploy top-down policies to encourage 'gender mainstreaming' or 'women's empowerment', or restrict attention to select topics such as sexual and gender-based violence, homophobia or workplace sexual harassment. ${ }^{9}$ Rarely is gender addressed as an issue of power that requires the transformation of deep-seated patriarchal structures across the entire range of themes, actors and contexts within which the effects of multiple layers of inequality are experienced and perpetuated.

In this special issue, we highlight the structural inequalities woven into the fabric of BHR frameworks, practices and scholarship, including 'the corporation' itself. As several of the papers show, the dominant ideologies and institutions that have shaped the form and purpose of the corporation are deeply gendered and racialized. Feminist approaches critique these attributes that form the DNA of the typical corporate structure, the global economy and international law. ${ }^{10}$

Although international human rights discourse has embraced the idea of gender as a social construct, in practice, international human rights and economic institutions and businesses tend to use biological sex as a proxy for gender and gender as a proxy for women. These truncated understandings of sex and gender have been critiqued by feminist scholars and practitioners who insist on the need to inject approaches to international law and human rights with intersectional framings that emphasize peoples' diversity and agency. ${ }^{11}$

As the contributions in this special issue show, current business structures perpetuate the exploitation of women, particularly women living in the Global South. The tropes of

\footnotetext{
${ }^{8}$ Catia Gregoratti, 'Cracks in the Corporatisation of Feminism' (2016) 13:6 Environmental Security in Transnational Contexts 922; Hester Eisenstein, 'Hegemonic Feminism, Neoliberalism and Womenomics: "Empowerment” Instead of Liberation?' (2017) 91 New Formations 35; Elisabeth Prügl, 'Neoliberalising Feminism' (2015) 20:4 New Political Economy 614; Catherine Rottenberg, 'The Rise of Neoliberal Feminism' (2014) 28:3 Cultural Studies 418; David Harvey, A Brief History of Neoliberalism (Oxford: Oxford University Press, 2005).

${ }^{9}$ Simons and Handl, note 2.

${ }^{10}$ John Linarelli, Margot Salomon and Muthucumaraswamy Sornarajah, The Misery of International Law: Confrontations With Injustice in the Global Economy (Oxford: Oxford University Press, 2018).

${ }^{11}$ Sari Kouvo and Zoe Pearson, Feminist Perspectives on Contemporary International Law: Between Resistance and Compliance? (Oxford: Hart Publishing, 2011); Brooke Ackerly, Universal Human Rights in a World of Difference (Cambridge: Cambridge University Press, 2008).
} 
'we're empowering women', 'we're giving women jobs' or 'we're unleashing women's untapped productivity' are challenged. While individual initiatives may contribute to small improvements in gender equality in specific contexts, we are sceptical about BHR approaches that do not at the same time identify how the agents and structures from which such initiatives emanate can simultaneously be the sites and causes of poverty and gender discrimination. We need to redirect the focus of the BHR discourse away from notions of 'empowering victims', towards the identification and transformation of the constitutive elements of the market and the actors within it that cause harm. Those who speak about 'empowerment', for example, must also recognize the ways in which they may be responsible for the disempowerment they now seek to remedy. Such empowerment discourses frequently see women as passive and in need of protection, rather than as agents. In other words, we need a feminist approach to BHR.

A feminist approach demands not only revised methodologies for identifying harm, but also new responses to such harm. These must be participatory, inclusive and transformative political solutions. ${ }^{12}$ Feminism provides a suite of methodologies that might be deployed to ensure that diverse and marginalized voices fully inform the creation, development and implementation of human rights norms, accountability and monitoring mechanisms. ${ }^{13}$ The emphasis in feminist thinking on women's autonomy, diversity and agency provides a crucial counter-balance to the essentialist, stereotypical and victim-centred narratives that appear in many corporate social responsibility (CSR) and BHR discourses on gender equality.

\section{A Feminist Approach to the Development of the Special Issue}

Feminism was not only a driver in the substance of the special issue: it was important to us as editors to ensure that our approach to the editorial process was moored in feminist practice and praxis.

As guest editors, we worked towards a non-hierarchical and supportive editorial process. Following the original call for papers, we received 55 abstracts, of which 21 developed into scholarly articles or 'Developments in the Field' pieces. We held several workshops with the authors to develop a communal, conversational approach to generating and elaborating ideas. Even though we were sadly unable to include all of the exciting and innovative papers that emerged through this process, we hope that the conversations and connections made will contribute to the consolidation of a broader community of gender, business and human rights practice.

From the outset, as an editorial team, we agreed to include the voices of early career researchers alongside more established scholars and practitioners from different geographical regions - not because this is a fashionable imperative but because perspective is precisely the theme of this special issue. The same applies to disciplinary diversity. While law tends to dominate the BHR field, it is in fact only one of several areas of expertise needed to fully capture and respond to business-related human rights abuses. We also set out to feature themes that may not usually be associated with BHR, but arguably warrant the attention of the BHR community from a feminist perspective. It is worth reflecting on the challenges encountered by the guest editors in striving towards diversifying the literature on BHR along these lines. Academic publishing has the effect of systematically marginalizing the

\footnotetext{
12 Silvia Federici, Re-Enchanting the World: Feminism and the Politics of the Commons (Oakland: PM Press, 2019); Nancy Fraser, 'Contradictions of Capital and Care' (2016) 100 New Left Review 99.

${ }^{13}$ Ackerly, note 11; Joanna Bourke Martignoni, 'A Feminist Methodology for Implementing the Right to Food in Agrarian Communities: Reflections From Cambodia and Ghana', The Journal of Peasant Studies (2021), 10.1080/03066150.2021.1928642 (accessed 11 November 2021).
} 
voices of young researchers, women, non-English speakers, local human rights activists, and perspectives from the Global South. These exclusions along the lines of race, language, perceived expertise and geographical location need to be named and addressed. Perspectives of black women from Africa and women from Asia, for instance, remain under-represented, notwithstanding the excellence of scholars in these regions.

The special issue calls into question the very dichotomy between practice and academia, instead recognizing that such domains exist in a more fluid relation and need to be situated and contextualized in order to draw attention to the partial nature of knowledge and experience. Many of the scholars in the special issue identify as activists, theorists and practitioners, rooting their theoretical work in practical feminist dilemmas and discourses, while also having a political objective to ensure that their research feeds into practice-based domains. Similarly, voices from the field contributing to the special issue have done so with a view to their experiences informing scholarly debates directly as agents, rather than as objects of such study. For the authors, theory informs practice, and practice informs theory.

Several pieces bring within the BHR rubric topics that have received little or no attention from the BHR world. For instance, the discussion of the role of not-for-profit organizations in surrogacy, the impact of marketing stereotypes on children, and the rights of women workers in flower farms in Kenya, have been analysed from the perspective of health, marketing, gender or labour rights - but rarely from the BHR perspective, until now. These pieces demonstrate the elision that a non-feminist approach to BHR may create.

The contributions challenge the benevolent commitments to gender equality in the form of 'women's empowerment', as illustrated in the papers on women's empowerment projects and the LGBTI+ Standards. The need to more firmly anchor BHR praxis within specific contexts and to consistently represent and reflect different experiences of gender is essential for diversifying current BHR scholarship.

The COVID-19 pandemic has been a persistent feature throughout the development of this special issue. The pandemic has deepened pre-existing inequalities and exposed the unacknowledged prejudices in economic, political and social systems. The gendered impact was visible across different sectors and industries, with labour market segregation in the health, education, childcare, service and retail industries being thrown into relief. While, as noted in several of the contributions in the special issue, the rhetoric around 'building back better' and ensuring that no-one is left behind in line with the 2030 Agenda for Sustainable Development is strong, it remains to be seen whether this momentum will result in meaningful change.

The effects of COVID-19 were particularly acute for authors whose burden of reproductive labour increased dramatically in response to school closures and family illness. Global data reveal that this experience is not unique and that the gender gap in academic publishing has further widened since $2020 .{ }^{14}$ Some of the authors could not complete their papers due to increased demands on their time to fulfil care responsibilities. As editors, we experienced all of these difficulties, highlighting the intractable imbrication of the personal with the professional. The theory and content of this special issue, therefore, was not abstract to us as women engaged in academic and human rights practice.

\section{Feminist Themes in Business and Human Rights and the Special Issue}

Three inter-connected themes emerged organically from the contributions in this special issue. The first theme is what we call 'bodies and embodiment'. By this we mean the ways in

\footnotetext{
${ }^{14}$ Molly M King and Megan E Frederickson, 'The Pandemic Penalty: The Gendered Effects of COVID-19 on Scientific Productivity' (2021) 7 Socius 1.
} 
which gendered bodies are constructed and commodified through their interactions with businesses and the market. The second theme is 'women's positionality in the marketplace'. This theme includes aspects of the perennial feminist concern with the so-called public/ private dichotomy and the manner in which women's reproductive labour is exploited while simultaneously remaining invisible within most corporate accountability and remedy frameworks. The final theme is that of 'borderlessness', which encapsulates the dialectic between local and global technologies, supply chains, norms and spaces and their impacts in defining the contours of and potential solutions to business-related human rights harms. While all the contributions touches on multiple themes, for the purpose of introducing them in this editorial we have grouped them within one of these three topic headings below.

\section{Bodies and Embodiment}

Many of the contributions highlight the ways in which the body, gender constructs and sex-based attributes are commodified by business actors. Although sex and gender-based discrimination are increasingly addressed within human rights frameworks and discourses, underlying prejudices and fault lines of discrimination remain. At the heart of these discussions lie numerous, generally implicit and frequently contradictory, assumptions about women's embodied difference from the normative white, heterosexual, middle class, cis-gender man. ${ }^{15}$ Much of the focus on gender in business contexts in workplace strategies such as equal opportunity or equal pay, and in community 'empowerment' projects is based on an instrumental 'business case' for women's human rights that leverages their 'intertwined subjectivities' as mothers, care-givers, community members and environmental custodians. ${ }^{16}$

The paper by Clare Patton, Marisa McVey and Ciara Hackett on the sexual and reproductive wellness industry, for example, draws attention to how women's bodies continue to be treated as marketable commodities. The female sexual and reproductive wellness industry is premised on the idea that the female body is faulty and needs fixing and purifying; ironically, positioning women as the autonomous and willing agents who must take charge of their bodies through personalized wellness efforts. The authors provide compelling examples of how products within this industry are designed and marketed to 'repair' perceived flaws in various stages of women's sexual and reproductive lifecycles, based on insufficient or non-existent medical evidence, with dangerous consequences for women's physical and mental health. This industry, however, has evaded scrutiny within the BHR field by positioning itself as an 'empowered' and legitimate response to women's sexual and reproductive choices. The industry's exploitative and often dangerous dimensions reveal the disjuncture between the 'private' sphere of personal individual wellness and the 'public' market, as well as the widespread failures of governments to provide accessible and good quality reproductive and sexual healthcare and education.

In her paper examining how indigenous women human rights defenders (WHRDs) overcome silencing practices, Nancy R Tapias Torrado, explores how the prevailing narratives of 'progress' and 'development' accompanying mega-projects in Latin America often stand in stark contrast to the lived experiences of indigenous women. Using a case study focusing on the Wayúu Women's Force mobilization in Colombia and drawing on the emerging 'braided action' theoretical framework, the paper illustrates how indigenous

\footnotetext{
${ }^{15}$ Judith Butler, Gender Trouble: Feminism and the Subversion of Identity (London: Routledge, 1990); Joan Wallach Scott, 'Gender: Still a Useful Category of Analysis?' (2010) 57:1 Diogenes 7.

${ }^{16}$ Anne C Bellows et al, Gender, Nutrition, and the Human Right to Adequate Food: Toward an Inclusive Framework (Abingdon: Routledge, 2015); Seema Arora-Jonsson, 'Virtue and Vulnerability: Discourses on Women, Gender and Climate Change' (2011) 21:2 Global Environmental Change 744.
} 
WHRDs, in departing from traditional gender and racial norms through their activism, are often met with specifically gendered and embodied silencing practices from actors outside and within their communities. It is through the resistance of indigenous WHRDs to megaprojects that are being proposed by governments and businesses as mechanisms for the 'empowerment' of local communities that indigenous women have been able to mobilize and reaffirm their power.

The pieces on sexual stereotypes in marketing and on not-for-profit surrogacy organizations provide further insights into the site of the female body as an exploitable commodity, while adding further important intersectional dimensions of age, race and class to the discussion. Bernadette Gutmann, Shreyasi Jha, Emer O’Doherty and Ranjavati Banerji examine the exacerbation of harmful gender and sexual stereotypes in marketing and advertising, particularly with respect to children and youth. The authors note that with the rapid expansion of children's media consumption online, the sexual and racialized stereotypes that characterize much global marketing and advertising can serve to reify idealized notions of how children should behave in line with social norms, including the sexualization of girls and promotion of toxic masculinity. They call on businesses to employ approaches to marketing that actively counter sexual stereotypes, rather than perpetuating and exploiting them.

In their contribution on the human rights implications of not-for-profit surrogacy organizations in cross-border commercial surrogacy, Yingyi Luo, Shelley Marshall and Denise Cuthbert suggest that the United Nations Guiding Principles on Business and Human Rights (UNGPs) might provide a useful framework for shaping regulatory approaches given the 'business' nature and extraterritorial dimensions of such transactions. Using Australia as a case study, the authors explore how not-for-profit organizations play a critical role in the 'business' of cross-border surrogacy and pose associated questions as to their self-positioning as altruistic and not-for-profit agents. Again, here we have insights into a 'private' space where the absence of regulation contributes directly to the abuse and exploitation of women's bodies. The piece also addresses important North-South dynamics through its particular focus on the rights of surrogate mothers in the Global South.

Collectively these contributions provide insights into how patriarchal and neoliberal structures position themselves as promoting women's agency; whereas in fact they continue to perpetuate gender norms that adhere to the systematic commodification and exploitation of women's bodies. They also draw attention to the absence of regulation in these domains. This is interesting, as implicit ideas about these sectors as 'private' spaces not to be prioritized for public regulatory efforts are called into question. There is a lack of gendered BHR analysis in these 'business enterprises' that commodify women's bodies. This also gives rise to the question: what other types of industries are eclipsed because of assumptions about the private nature of women's bodies?

\section{Women's Positionality in the Marketplace}

Almost all the contributions in the special issue raise questions regarding women's positionality in the marketplace. The issues explored by the contributors reflect longstanding feminist challenges and inquiries into questions around the so-called public/ private divide, the boundaries of domestic responsibilities and care, and the role of women's labour in economies. The contributions not only address such feminist inquiries but also consider how they influence foundational understandings of concepts such as 'empowerment', 'the corporation' and 'remedies' in BHR.

Several of the contributions, for example, analyse the systemic discrimination and exploitation that characterize and sustain the structure of many current business models, including value chains. In their contribution on how a human rights-informed 
understanding of the Sustainable Development Goals (SDGs) might be applied to promote gender justice in the fashion sector, Ramona Vijeyarasa and Mark Liu highlight a number of the structural factors - such as reliance on women's informal and unpaid labour, and supply chain buyer-supplier structures where sourcing companies can avoid responsibilities - that underpin current global value chains in fast fashion. Arguing that sustainability and gender justice are indispensable and intertwined, the authors identify how responsible consumption, taxation, participation and other themes should be viewed through a gender perspective and how the SDGs can offer concrete targets to hold governments and businesses accountable.

The focus on how gendered exploitation of labour in global value chains in fact forms the bedrock of such business models, is also explored by Mary Kuira in her piece on the adoption of a model sexual harassment policy within the flower sector in Kenya. The piece provides insights into a further critical aspect of women's labour in global business activities: sexual harassment. The piece calls attention to the endemic sexual harassment in the workplace - aided by structural power imbalances, hierarchical employment relations and lack of female managerial staff - that characterizes this industry. It focuses on the model policy as an example of how company-level sexual harassment policies and commitments can contribute to concrete industry changes.

Adding an access to remedy angle in their feminist analysis of the legal mechanisms for protection and repair in the Brazilian extractive industries, Juliana Bertholdi and Danielle Anne Pamplona explore how traditional conceptions of the public/private can contribute to the exclusion of women from remedial systems. The piece takes the Doce River dam disaster as a case study to illustrate how the sexual division of labour that focused on a male worker as the 'norm' prevented women from accessing compensation following the disaster. The fact that the women affected were not viewed as workers or family breadwinners meant that they were not included within remedial schemes. The authors argue that the application of gender-responsive international BHR frameworks can be an important guiding point for stimulating changes in legislation and practice at the national level in this regard.

The failure of BHR to effectively address informal economies is a further critical point of inquiry. Looking at mining, Lina M Céspedes-Báez, Enrique Prieto-Ríos and Juan P Pontón-Serra analyse whether the implementation of BHR frameworks in Colombia responds to the challenges posed by informal mining and gender-based violence and discrimination associated with the sector. While the mining sector has been considered key in Colombia's economic growth, informal mining has been linked to gender-based violence and discrimination. By examining the specific measures Colombia has devised to implement BHR, including two National Action Plans on Business and Human Rights (NAPs), the authors demonstrate the urgency of addressing informal economies, including informal mining, in BHR frameworks and initiatives.

Addressing four different industries in three different global regions, these contributions illustrate that the devaluation of women's labour - whether this be formal, informal or in the form of reproductive labour - remains one of the underlying contributing factors that sustains harmful business models and value chains across sectors and industries globally. The contributions offer concrete examples of what feminist scholars have been pointing to for decades, namely, how these dimensions are omitted in most current BHR analysis of state duty to protect frameworks and human rights due diligence approaches. What they highlight is precisely that we cannot treat sexual harassment, barriers to access to remedy or informal economies as tangential gendered issues within BHR. Rather, they are the fundamental and structural nodes of discrimination against women that sustain the marketplaces in which business operates. 
As two further contributions demonstrate, reimagining the global market will require overturning seemingly fixed concepts such as 'the corporation' itself.

In her contribution which questions the neoliberal underpinnings of corporate-supported 'women's empowerment' projects, Roseanne Russell hones in on how such projects work to transform women into 'gender capital' for business gain, rather than enabling broader notions of empowerment that go beyond women's role in market-based work. She argues that instead, the corporate responsibility to respect the human rights of women could be better supported by reorienting business away from its preoccupation with delivering value for shareholders, towards an approach that values women's unpaid socially reproductive labour.

In a further contribution, Charmika Samaradiwakera-Wijesundara calls into question the very existence and legitimacy of 'the company' in its current form. Rather than taking the conventional BHR starting point that accepts the corporate structure without critique, this paper attempts to reveal that granting of juristic personality is not a neutral, organic or inevitable product of the law and the market, but that 'the company' is a construct; and that underlying this construct are colonial ideologies that perpetuate racialized and gendered poverty and inequality. It is argued that by reorienting BHR away from juristic personality as a purportedly 'neutral' construct, the powers of the company might be curtailed, thereby interrupting these continuing colonial logics.

\section{Borderlessness}

'Borderlessness' encapsulates the dialectic between local and global, for instance in the field of technology or through the development and implementation of global BHR norms. Several of the contributions address the impacts of borderlessness in defining the contours of, and potential solutions to, business-related human rights harms. As discussed above, a number of the contributions examine gendered issues within global value chains and their extraterritorial dimensions. Each of the contributions that question the lack of accountability within the current corporate model has a 'borderless' dimension, emphasizing the interlinkages between our three ordering themes. In addition, several contributions speak to specific industries/aspects that are not contained within defined territorial boundaries, such as technology. Within the theme of borderlessness, we also introduce the contributions that interrogate processes of translating and implementing international norms in national and local contexts.

In her paper on gendered and racialized technologies, Grace Mutung'u uses a historical analysis of personal identification systems to demonstrate the colonial and patriarchal influences in new digital ID programmes being driven by the international development community in low and middle income countries. Using Kenya as a case study, the paper demonstrates how identity registration has gendered impacts, stemming from the historical exclusion of women in the system, lack of recognition of their contribution to new uses of the system as well as lack of engagement with women regarding remedies. Digital ID risks continuing and exacerbating these injustices, as it is based on the existing system. The article uses the UNGPs to analyse how decolonial approaches could be applied in digital ID to untangle it from colonial legacies, check the ever-increasing power of businesses involved in digital ID systems, and broaden intersectional understandings of human rights.

In their paper on norm development, Amanda Lyons and Cooper Christiancy examine the UN Standards of Conduct for Business on Tackling Discrimination against LGBTI People (LGBTI+ Standards). They observe that the BHR field and the international LGBTI+ human rights agenda have evolved almost entirely separately and that the LGBTI+ Standards is the primary effort that has been made to bridge this gap. Although drafted in a way that strongly 
aligns with the second pillar of the UNGPs on the corporate responsibility to respect, the authors observe that the dissemination of the LGBTI+ Standards has mainly been untethered from human rights frameworks and monitoring systems. The paper identifies the need to reassert the human rights foundations of the LGBTI+ Standards and leverage their existing momentum to set out a more robust research and policy agenda to meaningfully account for sexual orientation, gender identity and expression, and sex characteristics in BHR frameworks.

On the topic of the private military and security industry, Sorcha MacLeod and Nelleke van Amstel evaluate whether private military and security companies (PMSCs) integrate a gender perspective into their human rights policies and grievance procedures. The International Code of Conduct for Private Security Providers (ICoC) addresses gender and sexual and gender-based violence and explicitly requires PMSCs to integrate a gender perspective in their practices. By examining publicly available documents and policies required for PMSCs certified as complying with the ICoC, the authors find that despite increased attention to the potential for negative gender impacts in the sector, companies have not developed gender-responsive policies and procedures. The piece concludes that PMSCs have not yet shown the required holistic understanding of gendered impacts and barriers required to respect human rights, and that further efforts are needed in the sector.

Many of the contributions draw attention to the gaps and contradictions encountered in the translation of global BHR norms into regulatory frameworks at the national level. For example, the pieces on remedy in Brazil, informal mining in Colombia and sexual harassment in the Kenyan floriculture industry, suggest that international norms and frameworks such as the UNGPs and NAPs can play an important role in ensuring the gender responsiveness of BHR initiatives at the national level. Other contributions draw attention to failed attempts at integrating international norms into specific industries, such as the private military and security sector. These contributions illustrate that where international BHR norms, including those addressing gendered harms, remain focused on top-down initiatives, problems arise that might usefully be further explored in feminist BHR scholarship going forward.

\section{Conclusion}

A feminist approach to BHR that identifies and confronts the operations of patriarchy helps to render multiple forms of oppression visible. The contributions in the special issue reveal the ways in which class, race, ethnicity, age, indigeneity, colonialism and migration intersect to produce diverse gendered experiences of business-related harm that must be identified, prevented and remedied by states, companies and other duty-bearers. Taking a feminist approach to BHR means going beyond the inclusion of women within existing, unequal business structures and BHR frameworks. It requires laying down a challenge to neoliberalism as an ideology and as a practice that continues to obscure the intersectional nature of inequalities that are magnified through the workings of globalized economies. The contributions in this special issue reimagine approaches to BHR which make clear that these inequalities must and can be overcome to build more equitable and sustainable futures.

Acknowledgments. We would like to sincerely thank Mathilde Dicalou for her exceptional research and editing assistance in preparing the special issue. We would also like to thank Naadhirah Mayet, who has travelled this journey with us from the beginning, and Amina Ahmad for their research assistance and contributions. Putting together the special issue has been a three-year process that has involved discussions and debates with the contributing authors, colleagues, friends and family. We would like to thank everyone who has supported us throughout the process and contributed to the development of the ideas that have informed this introduction and the special issue as a whole. While this has been a collective effort, Jo, Harpreet and Boni would like to express their 
deep gratitude to Nora for her extraordinary contribution to bringing the issue to fruition. The special issue came together during the COVID-19 pandemic, which involved many personal and professional challenges for all involved in the publication process. In particular, we would like to pay tribute to the relatives and friends who passed away during this period.

Conflicts of interest. The authors declare none. 